\title{
Work-life imbalance and mental health among male and female employees in Switzerland
}

\section{Journal Article}

Author(s):

Hämmig, Oliver; Bauer, Georg

Publication date:

2009

Permanent link:

https://doi.org/10.3929/ethz-b-000018907

Rights / license:

In Copyright - Non-Commercial Use Permitted

Originally published in:

International Journal of Public Health 54(2), https://doi.org/10.1007/s00038-009-8031-7 


\title{
Work-life imbalance and mental health among male and female employees in Switzerland
}

\author{
Oliver Hämmig and Georg Bauer \\ Institute of Social and Preventive Medicine, University of Zurich, Switzerland \\ Submitted: 01 March 2008; revised: 30 July 2008, 06 November 2008; accepted: 01 December 2008 \\ Published online first: 26 February 2009
}

\section{Abstract}

Objectives: To investigate the prevalence and mental health effects of an unequal work-life balance (WLB) including potential gender differences.

Methods: A cross-sectional study based on a representative sample of the Swiss employed population aged 20 to 64 (women: $n=1661$; men: $n=1591$ ).

Results: Based on a single-item measure, more than every seventh employee in Switzerland indicated major difficulties combining work and private life. In certain socio-demographic categories, up to $30 \%$ showed such work-life conflict (WLC). For both genders, work-life imbalance turned out to be a risk factor affecting mental health. Employees with self-reported WLC presented a significantly higher relative risk for poor self-rated health (women: $\mathrm{aOR}=2.6 / \mathrm{men}$ : $\mathrm{aOR}=2.0$ ), negative emotions and depression ( $\mathrm{aOR}=3.0 / 3.1$ ), low energy and optimism ( $\mathrm{aOR}$ $=2.1 / 1.6)$, fatigue $(\mathrm{aOR}=2.4 / 2.6)$, and sleep disorders $(\mathrm{aOR}$ $=1.8 / 1.5$ ) compared to employees with no WLC.

Conclusions: Internationally, few data on the prevalence of WLC exist. In Switzerland, work-life imbalance is not a marginal phenomenon among the workforce and needs to be addressed as a notable public and mental health issue.

Keywords: Work-life conflict - Work-life balance - Mental health Gender differences - Switzerland.

\section{Introduction}

Against a backdrop of economic pressure and a changing understanding of social roles leading to an increased number of working mothers, single parents, and dual-income couples, juggling job and private life has become a growing challenge for employees. Thus, this issue of work-life balance (WLB) has generated considerable research interest over the past years. Numerous research articles can be found under the keywords "work-family balance" and "work-family conflict". Work-family balance is defined as "satisfaction and good functioning at work and at home with a minimum of role conflict" or as a "lack of conflict or interference between work and family roles"1. Role conflicts between work and family life - labelled work-family conflict (WFC) - occur "when demands of participation in one domain are incompatible with demands of participation in the other domain"2 or "when one's efforts to fulfil work role demands interfere with one's ability to fulfil family demands and vice versa" ${ }^{3}$.

In research on work-related health, the concept of WFC commonly appears as an antecedent for psychological distress and mental disorders in specific occupational groups ${ }^{4-8}$. With an increasing number of researchers focusing on this topic, a new field of research has emerged, which investigates the causes and health- or work-related effects of such role conflicts more broadly ${ }^{9-14}$. Various studies revealed a number of work- and health-related effects of WFC with strongest evidence for impeded work and life satisfaction ${ }^{2,5}, 12,14-18$. Health-related effects include increased substance abuse and especially problem drinking, greater psychological strain and distress, more frequent depression and mental disorders, burnout, and psychosomatic symptoms including lack of appetite and fatigue ${ }^{3-8,12,15,18-21}$. 
Despite the wealth of literature, research findings in the field of work-life integration or interference show a number of shortcomings and limitations ${ }^{12,14,22-26}$. The following ones are addressed and resolved by the present study:

- First, research is traditionally focused on role conflicts between paid work and family in the narrow sense. Singles or dual-income couples without minors living at home are usually excluded from study populations.

- Second, most studies investigate homogeneous, often middle-class population groups, limiting the generalisability and comparability of results. Only few studies used representative samples of the workforce ${ }^{3,19,27}$ or compared national samples between countries ${ }^{28}$. Thus, evidence on the prevalence of work-life imbalance is limited and inconsistent $^{19,27}$.

- Third, most studies and research results are from North America, which cannot be directly transferred to Europe. To date, only few scientific contributions from Germanspeaking countries have been published and none from Switzerland.

In light of these limitations, the study addressed the following research questions:

1. How prevalent is a perceived imbalance or role conflict between work and private life among employees in Switzerland? Which subgroups are particularly affected by such a work-life conflict (WLC)?

2. Is WLC a risk for poor (mental) health? Can the negative health effects documented in international studies on WFC and based on small, non-representative samples be confirmed for the whole employed population in Switzerland?

In addition to these research questions, possible differences between men and women in terms of prevalence and potential health effects of WLC were explored in this study, as gender differences have been reported in some international studies $^{19,29}$.

\section{Methods}

\section{Database and study sample}

To ensure generalisability of the findings, the present study used survey data from the Swiss Household Panel (SHP). The publicly funded SHP provides data from a nationally representative sample and covers differing living and working conditions as well as various aspects of health and well-being among people living in Switzerland. SHP data are collected every year since 1999 using computer-assisted telephone interviewing (CATI).
The regionally stratified SHP sample initially included 5'074 households and 7'799 people aged over 13. As dropouts between 1999 (wave 1) and 2006 (wave 8) reached nearly 50\% of the original sample, and the questionnaire of 1999 was revised significantly for subsequent collections, the present cross-sectional study used data from the second wave in 2000 to bolster representativity and statistical power. This sample covers $91 \%$ of the initial sample including 4'532 households with 7'073 people interviewed. A subsample of 3'252 employees aged 20 to 64 years, both with and without children, was used for analysis. To ensure results which best represent the Swiss workforce, the data were weighted according to the last census in 2000 by gender, age, nationality, and region.

\section{Measures}

The breadth of topics covered by the SHP and repeated data collection from the same participants limited the number of questions for each topic. One strategy of the SHP was to draw mainly on single-item measures with differentiated response categories (mostly 11-point Likert-scaled items) instead of using multiple-item measures with less differentiated or even dichotomous response categories. This allows for better measurement and monitoring of social changes in living conditions in the future, another key goal of the SHP.

Work-life imbalance: In the 2000 SHP dataset, there is only one yes/no question indicating WLC or work-life imbalance: "In the past year, have you experienced considerable difficulties in reconciling your work with your family and/or private life?"

Personal and work-related factors: In order to characterise potential risk groups among the entire workforce, demographic variables (age, gender, education), work-related variables (job status, employment status, overtime, commuting time, time flexibility, decision latitude, job security), and variables describing aspects of private life (time spent on housekeeping, number of under-age children living at home, relationship status) were used.

Health outcomes: Health effects of WLC were measured by five indicators on general well-being and mental health: self-rated health ("How do you feel right now?"), negative emotions and depression ("Do you often have negative feelings such as having the blues, being dejected, suffering from anxiety or depression?"), energy and optimism ("Do you often have plenty of strength, energy and optimism?"), fatigue ("Over the last year, have you suffered at least once a month from general weakness, weariness, or lack of energy?"), and sleep disorders ("Over the last year, have you suffered at least once a month from difficulty falling asleep or insomnia?"). The first question is a 5-point Likert scaled item, the second and third are 11-point Likert scales, and the last two items are yes/no questions. 


\begin{tabular}{|c|c|c|c|c|c|c|}
\hline & \multicolumn{3}{|c|}{ Men } & \multicolumn{3}{|c|}{ Women } \\
\hline & $N^{1)}$ & $\%^{2)}$ & p-value & $N^{1)}$ & $\%^{2)}$ & p-value \\
\hline Employees in total & 1591 & 14.3 & & 1661 & 14.9 & \\
\hline \multicolumn{7}{|l|}{ Age } \\
\hline $20-29$ years & 276 & 15.0 & .000 & 334 & 17.1 & .000 \\
\hline $30-39$ years & 477 & 18.4 & & 497 & 20.3 & \\
\hline $40-49$ years & 451 & 16.7 & & 459 & 15.5 & \\
\hline $50-64$ years & 387 & 7.2 & & 371 & 6.3 & \\
\hline \multicolumn{7}{|l|}{ Education } \\
\hline none or Secondary School Certificate & 114 & 6.2 & .000 & 153 & 7.8 & .000 \\
\hline Occupational School Certificate & 651 & 12.1 & & 797 & 12.2 & \\
\hline College Cert. or Bachelors Degree & 432 & 15.3 & & 471 & 17.6 & \\
\hline Masters or Doctoral Degree & 362 & 22.4 & & 211 & 26.5 & \\
\hline \multicolumn{7}{|l|}{ Job status (occupational position) } \\
\hline other & 111 & 6.6 & .000 & 186 & 12.1 & .001 \\
\hline production position (standard level) & 736 & 12.3 & & 1078 & 13.2 & \\
\hline supervisory/training position & 565 & 16.2 & & 336 & 20.5 & \\
\hline management position & 177 & 23.4 & & 59 & 29.5 & \\
\hline \multicolumn{7}{|l|}{ Number of under-age children } \\
\hline none & 882 & 11.4 & .000 & 991 & 12.2 & .002 \\
\hline 1 & 242 & 16.9 & & 262 & 17.9 & \\
\hline 2 & 302 & 17.0 & & 280 & 20.6 & \\
\hline $3+$ & 165 & 22.0 & & 127 & 20.4 & \\
\hline \multicolumn{7}{|l|}{ Relationship status } \\
\hline no long-term relationship & 231 & 7.6 & .005 & 310 & 12.6 & .296 \\
\hline living with partner/spouse & 1202 & 15.1 & & 1131 & 15.0 & \\
\hline not living with partner & 156 & 17.8 & & 217 & 17.9 & \\
\hline \multicolumn{7}{|l|}{ Time spent on housekeeping } \\
\hline$\leq 5 \mathrm{~h} /$ week & 1020 & 13.5 & .341 & 371 & 14.9 & .978 \\
\hline $6-20 \mathrm{~h} /$ week & 531 & 16.1 & & 899 & 14.9 & \\
\hline$>20 \mathrm{~h} /$ week & 18 & 13.0 & & 355 & 15.4 & \\
\hline \multicolumn{7}{|l|}{ Employment status } \\
\hline part-time (<20 h/week) & 41 & 12.2 & .035 & 465 & 11.4 & .076 \\
\hline part-time (20 to $39 \mathrm{~h} /$ week) & 142 & 21.5 & & 610 & 16.2 & \\
\hline full-time (40+ h/week) & 1400 & 13.8 & & 564 & 16.3 & \\
\hline \multicolumn{7}{|l|}{ Frequent overtime work } \\
\hline none & 641 & 9.7 & .000 & 904 & 13.0 & .009 \\
\hline voluntary & 504 & 18.0 & & 274 & 20.4 & \\
\hline ordered & 229 & 21.0 & & 140 & 19.4 & \\
\hline \multicolumn{7}{|l|}{ Commuting time to work } \\
\hline$\leq 30$ minutes & 735 & 13.6 & .483 & 871 & 14.1 & .318 \\
\hline $31-60$ minutes & 546 & 13.5 & & 509 & 15.6 & \\
\hline$>60$ minutes & 247 & 16.5 & & 199 & 18.6 & \\
\hline \multicolumn{7}{|l|}{ Time flexibility at work } \\
\hline flextime & 870 & 16.8 & .012 & 640 & 17.2 & .121 \\
\hline fixed work schedule & 611 & 11.9 & & 899 & 13.1 & \\
\hline shift work & 108 & 10.9 & & 116 & 15.8 & \\
\hline \multicolumn{7}{|l|}{ Decision latitude at work } \\
\hline no influence or autonomy at work & 585 & 18.7 & .000 & 398 & 17.5 & .280 \\
\hline provide advice on management & 530 & 15.3 & & 535 & 14.8 & \\
\hline taking part in decision making & 474 & 8.9 & & 722 & 13.6 & \\
\hline \multicolumn{7}{|l|}{ Job security } \\
\hline very secure & 711 & 12.8 & .012 & 784 & 13.2 & .021 \\
\hline fairly secure & 719 & 14.3 & & 675 & 15.0 & \\
\hline insecure & 112 & 23.0 & & 138 & 23.1 & \\
\hline
\end{tabular}

Table 1. Prevalence (\%) of WLC for male and female employees according to differing aspects of work and private life.

${ }^{1)}$ unweighted data; ${ }^{2)}$ weighted data 


\begin{tabular}{|c|c|c|c|c|c|c|}
\hline & \multicolumn{3}{|c|}{ Men } & \multicolumn{3}{|c|}{ Women } \\
\hline & $\mathbf{N}^{1)}$ & $\%^{2)}$ & p-value & $\mathbf{N}^{1)}$ & $\%^{2)}$ & p-value \\
\hline Employees in total & 1591 & 14.3 & & 1661 & 14.9 & \\
\hline \multicolumn{7}{|l|}{ Self-rated health } \\
\hline good to very good (1-2) & 1452 & 13.8 & .045 & 1437 & 13.5 & .000 \\
\hline moderate to very poor $(3-5)$ & 139 & 19.6 & & 223 & 23.2 & \\
\hline \multicolumn{7}{|l|}{ Negative emotions and depression } \\
\hline rarely to never $(0-4)$ & 1451 & 13.0 & .000 & 1420 & 12.8 & .000 \\
\hline occasionally to permanently $(5-10)$ & 138 & 26.7 & & 241 & 25.9 & \\
\hline \multicolumn{7}{|l|}{ Energy and optimism } \\
\hline occasionally to never (0-5) & 174 & 17.7 & .161 & 244 & 22.5 & .000 \\
\hline frequently to permanently $(6-10)$ & 1413 & 13.9 & & 1417 & 13.4 & \\
\hline \multicolumn{7}{|l|}{ Fatigue (weakness, weariness) } \\
\hline no & 1205 & 11.3 & .000 & 1004 & 10.7 & .000 \\
\hline yes & 385 & 23.4 & & 657 & 20.8 & \\
\hline \multicolumn{7}{|l|}{ Sleep disorders (incl. insomnia) } \\
\hline no & 1229 & 13.2 & .017 & 1196 & 13.3 & .009 \\
\hline yes & 361 & 18.0 & & 464 & 18.7 & \\
\hline
\end{tabular}

Table 2. Proportion (\%) of men and women with difficulties combining work and private life among healthy groups compared to unhealthy groups.

${ }^{1)}$ unweighted data; ${ }^{2)}$ weighted data

\section{Statistical analysis}

To assess risk groups for WLC, prevalence rates for all employees in Switzerland and various subgroups according to demographic and work-related factors were calculated, stratified by gender.

Health effects of work-life imbalance were studied by calculating prevalence rates for various health variables. P-values indicating statistical significance of differences between subcategories were computed for all cross-tabulations. Furthermore, multiple logistic regression analyses were applied to calculate partial odds ratios and thus to determine the relative risk of having health problems in the presence of WLC. Consequently, Likert-scaled health variables were recoded to binary variables. The regression analyses were adjusted for age, education, and job status. Analyses were performed separately for men and women.

\section{Results}

\section{Prevalence of work-life imbalance}

Regarding the first research question on the distribution of work-life imbalance among Swiss employees, in 2000 14.6\% of employees aged 20 to 64 reported major difficulties combining work and private life. No significant gender differences overall, but remarkable differences between prevalence rates for various subgroups could be seen (see Table 1), ranging from $6 \%$ (unskilled men) to $30 \%$ (women in management position).

The lack of difference in the prevalence rate of work-life imbalance between male and female employees turns out to be a fallacy as women with higher education, in full-time employment and higher occupational positions are small in number, but have greater difficulties combining work and private life compared to their male counterparts. More or less the same risk groups with above average prevalence rates for both genders can be found. These risk groups include people between 30 and 40 years of age, people with higher education, especially those with graduate degrees, and people in higher occupational positions. Furthermore, full-time, overtime, and flextime workers as well as long commuters are at special risk of having WLC. Looking at aspects of private life, those with several under-age children living at home or a partner who is not living in the same household are at risk.

\section{Health effects of work-life imbalance}

Table 2 shows that prevalence rates of WLC are higher among employed men and women with increased (mental) health problems. Multiple logistic regression analyses confirm that work-life imbalance bears a relative risk for poor health. Statistically significant adjusted odds ratios (aOR) of more than 1.5 can be seen throughout the analyses for the five health indicators and for both genders (see Tables 3 and 4). However, negative health effects of work-life imbalance seem to be slightly stronger in women than in men. 
Table 3. Effects of work-life imbalance on various (mental) health outcomes for female employees aged 20 to 64 in Switzerland.

\begin{tabular}{|c|c|c|c|c|c|c|c|c|c|c|c|}
\hline & \multirow[b]{2}{*}{$\mathbf{N}$} & \multicolumn{2}{|c|}{$\begin{array}{l}\text { Moderate to very } \\
\text { poor self-rated health }\end{array}$} & \multicolumn{2}{|c|}{$\begin{array}{l}\text { Neg. emotions and } \\
\text { depression (5-10) }\end{array}$} & \multicolumn{2}{|c|}{$\begin{array}{l}\text { Low energy and } \\
\text { optimism (0-5) }\end{array}$} & \multicolumn{2}{|c|}{ Regular fatigue } & \multicolumn{2}{|c|}{$\begin{array}{l}\text { Regular } \\
\text { sleep disorders }\end{array}$} \\
\hline & & $\mathrm{OR}^{\dagger}$ & $95 \%-\mathrm{Cl}$ & $\mathrm{OR}^{\dagger}$ & $95 \%-\mathrm{Cl}$ & $O R^{\dagger}$ & $95 \%-\mathrm{Cl}$ & $\mathrm{OR}^{\dagger}$ & $95 \%-\mathrm{Cl}$ & $\mathrm{OR}^{\dagger}$ & $95 \%-\mathrm{Cl}$ \\
\hline \multicolumn{12}{|c|}{$\begin{array}{l}\text { Difficulties combining work } \\
\text { and private life }\end{array}$} \\
\hline No & 1400 & 1.00 & & 1.00 & & 1.00 & & 1.00 & & 1.00 & \\
\hline Yes & 260 & 2.56 & $1.74-3.77$ & 2.97 & $2.08-4.25$ & 2.11 & $1.46-3.04$ & 2.39 & $1.76-3.24$ & 1.81 & $1.31-2.49$ \\
\hline $\mathrm{N}$ & 1660 & & 1628 & & 1629 & & 1629 & & 1629 & & 1628 \\
\hline
\end{tabular}

${ }^{\dagger}$ Odds Ratios are additionally adjusted for age, education, and job status (occupational position); bold figures = highly significant OR ( $<<.01$ )

Table 4. Effects of work-life imbalance on various (mental) health outcomes for male employees aged 20 to 64 in Switzerland.

\begin{tabular}{|c|c|c|c|c|c|c|c|c|c|c|c|}
\hline & \multirow[b]{2}{*}{ N } & \multicolumn{2}{|c|}{$\begin{array}{l}\text { Moderate to very } \\
\text { poor self-rated health }\end{array}$} & \multicolumn{2}{|c|}{$\begin{array}{l}\text { Neg. emotions and } \\
\text { depression (5-10) }\end{array}$} & \multicolumn{2}{|c|}{$\begin{array}{l}\text { Low energy and } \\
\text { optimism (0-5) }\end{array}$} & \multicolumn{2}{|c|}{ Regular fatigue } & \multicolumn{2}{|c|}{$\begin{array}{l}\text { Regular } \\
\text { sleep disorders }\end{array}$} \\
\hline & & $O R^{\dagger}$ & $95 \%-\mathrm{Cl}$ & $O R^{\dagger}$ & $95 \%-\mathrm{Cl}$ & $\mathbf{O R}^{\dagger}$ & $95 \%-\mathrm{Cl}$ & $\mathrm{OR}^{\dagger}$ & $95 \%-\mathrm{Cl}$ & $\mathrm{OR}^{\dagger}$ & $95 \%-\mathrm{Cl}$ \\
\hline \multicolumn{12}{|c|}{$\begin{array}{l}\text { Difficulties combining } \\
\text { work and private life }\end{array}$} \\
\hline No & 1347 & 1.00 & & 1.00 & & 1.00 & & 1.00 & & 1.00 & \\
\hline Yes & 243 & 1.98 & $1.28-3.07$ & 3.05 & $2.05-4.54$ & 1.59 & $1.05-2.41$ & 2.63 & $1.95-3.54$ & 1.54 & $1.12-2.10$ \\
\hline $\mathrm{N}$ & 1590 & & 1555 & & 1554 & & 1552 & & 1554 & & 1554 \\
\hline
\end{tabular}

${ }^{+}$Odds Ratios are additionally adjusted for age, education, and job status (occupational position); bold figures = highly significant $O R$ ( $p<.01$ )

\section{Discussion}

The aims of the present study were to estimate the distribution of work-life imbalance among employees in Switzerland and specific subgroups, and to investigate possible effects of WLC on (mental) health.

Regarding the first research question, role conflicts in terms of combining work and private life are experienced by $14.6 \%$ of all surveyed employees in Switzerland. The prevalence of work-life imbalance or WLC is likely to be underestimated in this survey as the yes/no question asked was somewhat restrictive ("Have you experienced major difficulties in reconciling your work with your private life?"). Employees with minor difficulties combining work and private life are excluded a priori. The prevalence of WLC in Switzerland is expected to be relatively high, given the long work week and frequent overtime. The occurrence of irregular work hours such as evening, night, and weekend shifts is increasing. ${ }^{30}$ Furthermore, there is a high workforce participation rate among women and mothers of young children. The proportion of 15 to 64-year old women in Switzerland engaged in paid work increased from $49 \%$ in 1970 to over $70 \%$ in 2000 . The proportion of employed women aged 25 to 45 with at least one child under 6 - i.e. pre-school age - rose from $40 \%$ to $62 \%$ in just one decade (from 1990 to 2000), according to the last Swiss census. Thus, in Switzerland, the number of people engaged concurrently in paid work and parenthood, care for family members, or housekeeping duties has dramatically increased over the last decades. Unfortunately, only very few international studies reveal prevalence rates of WFC based on data from samples that are representative for the whole working or employed population at a national level making international comparisons almost impossible. Jansen et al.'s ${ }^{19}$ study based on two-year follow-up data from the Maastricht Cohort Study on "Fatigue at Work" is the only one that can be compared to the present study due to its use of a single-item measure of WFC and the comparable wording and identical answer categories (yes/no) of the question ("Are you able to adequately combine work and family life?"). In that Dutch cohort study, only $10.8 \%$ of the sample indicated being unable to combine work and private life adequately (in 1998). If only employees who work at least 20 hours per week are considered in the present study (as in the Jansen et al.'s ${ }^{19}$ study), the prevalence rate is $15.1 \%$ (in 2000). It appears that Swiss employees (aged 20 to 64) experience more WLC than Dutch employees (aged 18 to 65).

Regardless of the overall prevalence of WLC, the present study shows a range of aspects related to high prevalence rates of work-life imbalance. In accordance with other studies ${ }^{8,} 19,27$, a high workload (including full-time and overtime work), 
long commuting time to work, or job insecurity emerged as risk factors for WLC. Higher education or occupational positions, as well as having under-age children living in the same household are further factors related to an increased prevalence of WLC. Higher levels of decision latitude, in contrast, are associated with less difficulties combining work and private life, especially in men.

Going against expectation, WLC is not becoming more prevalent with increasing housekeeping duties. This may be explained by the fact that employment status and activity level respectively decreases with increasing housekeeping duties and thus sufficient time is allocated to this extensive family or housekeeping role.

Time flexibility at work seems to be a risk factor more than a protective factor regarding WLC. This may be because flextime often goes along with overtime work, which in turn is associated with higher levels of WLC. More rigid work schedules, on the contrary, imply greater predictability of work hours and therefore a better work-life balance.

As for the second research question, negative health effects of WLC could be shown. Adjusted odds ratios ranged between 1.5 and 3.1 and were mostly statistically significant. These values cannot be readily compared to other studies on WFC, as different statistical methods were used and different population groups surveyed. However, findings of increased mental health problems, particularly fatigue and emotional disorders such as negative emotions and depression, resulting from increased WLC among the Swiss workforce match previous reports from specific occupational groups in other countries $^{4,8,19,21,27 .}$.

Although the health indicators used are single-item measures without exception and many researchers have raised concerns regarding the use of single items especially when measuring multi-dimensional constructs, there is some support and evidence from health research and other fields of research that single-item measures may be equally valid and reliable as multiple-item measures and can therefore serve as reasonable substitutes for them ${ }^{31-34}$. The single-item question on self-rated health, which is well-established as a strong and independent predictor of morbidity and mortality ${ }^{35}$, is widely used as a global measure of general health status in epidemiology and social science ${ }^{36}$.

With respect to gender differences, it can be seen that female employees in Switzerland overall do not show higher levels of WLC or work-life imbalance as their male colleagues. However, when the significantly lower numbers of women in full-time employment and higher occupational positions are taken into consideration, a comparison between men and women reveals a major gender difference. If men and women working full-time or in higher occupational posi- tions (e.g., as supervisors and managers) are compared, women show higher prevalence rates of WLC than men. This is probably due to the fact that women, whether working or not, still play a bigger part in caring for children and housekeeping. As far as mental health and general well-being are concerned, women tend to be slightly more affected by WLC than men.

As stated in the introduction, the present study had several strengths, including the application of an expanded WLC instead of a WFC framework, providing representative data at the national level and elucidating gender differences. Also, the study demonstrated the usefulness of the SHP as an economical way for a population-based, explorative study on timely and innovative topics such as WLB, filling a research gap in Switzerland by providing initial scientific evidence on the public health relevance of an issue that is broadly discussed in public.

At the same time, using the SHP database created several potential limitations.

First, only one variable was to measure work-life imbalance, possibly limiting the validity of this single-item measure. Nevertheless, plausible differences in the prevalence of WLC for different subgroups could be shown. Furthermore, our results are not only widely consistent for diverse mental health outcomes and for both men and women but also with findings from international studies.

A second limitation is the use of cross-sectional data which makes causal inferences impossible. Yet strong, consistent associations between WLC and diverse mental health outcomes are at least a good indication of a potential cause-effect relationship, particularly when adjusting for different potential confounders and stratifying by gender.

Third, since later waves of the SHP suffer from high dropout, early data from the year 2000 were used in order obtain highly representative results and for better comparisons with earlier studies covering prevalence data. This implies that the prevalence rates obtained do not exactly reflect current levels of WLC that might have changed in the meantime. However, the findings for risk groups, risk factors and health outcomes should only be affected in a minor way by changes over time in overall prevalence.

\section{Conclusions}

For the first time, findings from international studies could be replicated and confirmed for Switzerland and with a nationally representative study sample for all employees (excluding those who are self-employed). As previous international researchers based their investigations on a more confined focus on work-family conflict only, and their measurement instruments, study populations, and settings differed from those 
applied in the current study, it was not necessarily expected that the present results would confirm the previous findings by and large.

Although in principle only longitudinal studies and data analyses can indicate causality, current cross-sectional data show clear and plausible evidence of differences between certain groups in relation to work-life imbalance. These are groups with higher demands at work or in private life. Also, as expected and found in previous studies, WLC has been shown to be closely associated with general and mental health impairments and psychological ill-being. With the identification of risk factors and risk groups, this study provides relevant information for the planning of interventions in mental health promotion at the interface between work and private life.

In conclusion, the present study demonstrates that a lack of WLB is not a marginal phenomenon among employees in Switzerland. It also provides strong empirical evidence for the importance of WLC as a predictor or risk factor of poor mental health. In light of an observed increase in mental health problems in Switzerland ${ }^{37}$ as in many other countries and of increasing rates of morbidity, disability and even mortality due to mental illness ${ }^{38}$, the concept and phenomenon of WLC as a mental health determinant needs to be addressed and should get higher priority in health research as a notable public health issue of increasing importance.

Further research is needed to shed more light on the distribution of work-life imbalance among the Swiss workforce, applying more specific and validated measurement items. Preferably, an internationally recognised instrument should be used to facilitate international comparisons.

\section{Acknowledgements}

This study has been realized using the data collected by the Swiss Household-Panel, a project financed by the Swiss National Science Foundation Program SPP "Switzerland Towards the Future" (Grant no. 5004-53205). Additionally, data analysis for the current study has been financially supported by the Swiss National Science Foundation (Grant no. 020040100725).

\section{References}

1. Frone MR. Work-Family Balance. In: Quick JC, Tetrick LE, eds. Handbook of Occupational Health Psychology. Washington: American Psychological Association; 2003:143-63.

2. Adams GA, King LA, King DW. Relationships of job and family involvement, family social support, and work family conflict with job and life satisfaction. J Appl Psychol 1996;81:411-20.

3. Frone MR. Work-family conflict and employee psychiatric disorders: the national comorbidity survey. J Appl Psychol 2000;85:888-95.

4. Hammer TH, Saksvik PO, Nytro K, Torvatn H, Bayazit M. Expanding the psychosocial work environment: workplace norms and work-family conflict as correlates of stress and health. J Occup Health Psychol 2004;9:83-97.

5. Judge TA, Colquitt JA. Organizational justice and stress: the mediating role of work-family conflict. J Appl Psychol 2004;89:395-404.

6. Grzywacz JG, Bass BL. Work, family, and mental health: testing different models of workfamily fit. J Marr Fam 2003;65:248-61.

7. Schieman S, McBrier DB, Gundy KV. Hometo-work conflict, work qualities, and emotional distress. Sociological Forum 2003;18:137-64.

8. Smith Major V, Klein KJ, Ehrhart MG. Work time, work interference with family, and psychological distress. J Appl Psychol 2002;87:427-36.
9. Ford MT, Heinen BA, Langkamer KL. Work and family satisfaction and conflict: A meta-analysis of cross-domain relations. J Appl Psychol 2007;92:57-80.

10. Byron K. A meta-analytic review of workfamily conflict and its antecedents. J Vocat Behav 2005;67:169-98.

11. Campbell Clark S. Work cultures and work/ family balance. J Vocat Behav 2001;58:348-65.

12. Allen TD, Herst DEL, Bruck CS, Sutton M. Consequences associated with work-to-family conflict: a review and agenda for future research. J Occup Health Psychol 2000;5:278-308.

13. Lewis $S$, Cooper CL. The work-family research agenda in changing contexts. J Occup Health Psychol 1999;4:382-93.

14. Kossek EE, Ozeki C. Work-family conflict, policies, and the job-life satisfaction relationship: A review and directions for organizational behavior human resources research. J Appl Psychol 1998;83:139-49.

15. Van Rijswijk K, Bekker MHJ, Rutte CG, Croon MA. The relationships among part-time work, work-family interference, and well-being. J Occup Health Psychol 2004;9:286-95.

16. Bonebright CA, Clay DL, Ankenmann RD. The relationship of workaholism with work-life conflict, life satisfaction, and purpose in life. J Counsel Psychol 2000;47:469-77.
17. Perrewé PL, Hochwarter WA, Kiewitz C. Value attainment: an explanation for the negative effects of work-family conflict on job and life satisfaction. J Occup Health Psychol 1999;4:318-26.

18. Adams GA, Jex SM. Relationships between time management, control, work-family conflict, and strain. J Occup Health Psychol 1999;4:72-7.

19. Jansen NWHM, Kant IP, Kristensen TSP, Nijhuis FJNP. Antecedents and consequences of work-family conflict: a prospective cohort study. J Occup Environ Med 2003;45:479-91.

20. Burke RJ, Greenglass ER. Work-family conflict, spouse support, and nursing staff well-being during organizational restructuring. J Occup Health Psychol 1999;4:327-36.

21. Frone MR, Russell M, Barnes GM. Workfamily conflict, gender, and health-related outcomes: a study of employed parents in two community samples. J Occup Health Psychol 1996;1:57-69.

22. Casper WJ, Eby LT, Bordeaux C, Lockwood A, Lambert D. A review of research methods in IO/OB work-family research. J Appl Psychol 2007;92:28-43.

23. Eikhof DR, Warhurst C, Haunschild A. Introduction: what work? what life? what balance?: critical reflections on the work-life balance debate. Employee Relations 2007;29:325-33. 
24. Badura B, Vetter C. «Work-Life-Balance»Herausforderung für die betriebliche Gesundheitspolitik und den Staat. In: Badura B, Schellschmidt H, Vetter C, eds. Fehlzeiten-Report 2003 -

Zahlen, Daten, Analysen aus allen Branchen der Wirtschaft Wettbewerbsfaktor Work-Life-Balance Betriebliche Strategien zur Vereinbarkeit von Beruf, Familie und Privatleben. Berlin/Heidelberg: Springer; 2004:5-17.

25. Parasuraman S, Greenhaus JH. Toward reducing some critical gaps in work-family research. Hum Resour Manage R 2002;12:299-312.

26. Westman M, Piotrkowski C. Introduction to the special issue: work-family research in occupational health psychology. J Occup Health Psychol 1999 4:301-6.

27. Kinnunen U, Mauno S. Antecedents and outcomes of work family conflict among employed women and men in Finland. Human Relations 1998;51:157-77.

28. Spector PE, Cooper CL, Poelmans S, et al. A cross-national comparative study of workfamily stressors, working hours, and well-being: China and Latin America versus the Anglo world. Personnel Psychology 2004;57:119-42.

29. Kinnunen U, Geurts S, Mauno S. Work-tofamily conflict and its relationship with satisfaction and well-being: a one-year longitudinal study on gender differences. Work and Stress 2004;18:1-22.
30. Oesch D. Arbeitszeiten in der Schweiz - eine Untersuchung der Entwicklung in 14 Branchen. Eine Studie im Auftrag des Schweizerischen Gewerkschaftsbundes: Schweizerischer Gewerkschaftsbund; 2001.

31. DeSalvo KB, Fisher WP, Tran K, Bloser N, Merrill W, Peabody J. Assessing measurement properties of two single-item general health measures. Quality of Life Research 2006;15:191-201.

32. Robins RW, Hendin HM, Trzesniewski KH. Measuring global self-esteem: construct validation of a single-item measure and the Rosenberg self-esteem scale. Pers Soc Psychol Bull 2001; 27:151-61.

33. Rohland BM, Kruse GR, Rohrer JE. Validation of a single-item measure of burnout against Maslach Burnout Inventory among physicians. Stress and Health 2004;20:75-9.

34. Cunny KA, Perri M. Single item vs multiple item measures of health-related quality of life. Psychol Rep 1991;69:127-30.

35. Idler EL, Benyamini Y. Self-rated health and mortality: a review of twenty-seven community studies. J Health Soc Behav 1997;38:21-37.
36. Agyemang C, Denktas S, Bruijnzeels M, Foets M. Validity of the single-item question on self-rated health status in first generation Turkish and Moroccans versus native Dutch in the Netherlands. Public Health 2006;120:543-50.

37. Perrig-Chiello $P$. Mental health in public health - the necessity of a life-span perspective. Int J Public Health 2007;52:129-30.

38. Piko B. New challenges for mental health in public health. Int J Public Health 2007;52:12728.

\section{Address for correspondence}

Oliver Hämmig, PhD, MPH

Division of Public and Organizational Health

Institute of Social and Preventive Medicine, University of Zurich

Center for Organizational and Occupational Sciences, ETH Zurich

Hirschengraben 84

8001 Zurich

Switzerland

Tel.: ++41 446344850

Fax: ++41 446344986

E-mail: haemmigo@ifspm.uzh.ch ohaemmig@ethz.ch
To access this journal online: http://www.birkhauser.ch/IJPH 